\title{
BMJ open The varying role of the GP in the pathway between colonoscopy and surgery for colorectal cancer: a retrospective cohort study
}

\author{
David Goldsbury, ${ }^{1}$ Mark Harris, ${ }^{2}$ Shane Pascoe, ${ }^{2}$ Michael Barton, ${ }^{3}$ Ian Olver, ${ }^{4}$ \\ Allan Spigelman, ${ }^{5}$ Justin Beilby, ${ }^{6}$ Craig Veitch, ${ }^{7}$ David Weller, ${ }^{8}$ Dianne L O'Connell ${ }^{1}$
}

To cite: Goldsbury D, Harris M, Pascoe S, et al. The varying role of the GP in the pathway between colonoscopy and surgery for colorectal cancer: a retrospective cohort study. BMJ Open 2013;3:e002325. doi:10.1136/bmjopen-2012002325

- Prepublication history for this paper are available online. To view these files please visit the journal online (http://dx.doi.org/10.1136/ bmjopen-2012-002325).

Received 9 November 2012 Accepted 8 February 2013

This final article is available for use under the terms of the Creative Commons Attribution Non-Commercial 2.0 Licence; see http://bmjopen.bmj.com

For numbered affiliations see end of article.

Correspondence to David Goldsbury; davidg@nswcc.org.au

\section{ABSTRACT}

Objectives: To describe general practitioner (GP) involvement in the treatment referral pathway for colorectal cancer (CRC) patients.

Design: A retrospective cohort analysis of linked data. Setting: A population-based sample of CRC patients diagnosed from August 2004 to December 2007 in New South Wales, Australia, using the 45 and Up Study, cancer registry diagnosis records, inpatient hospital records and Medicare claims records.

Participants: 407 CRC patients who had a colonoscopy followed by surgery.

Primary outcome measures: Patterns of GP consultations between colonoscopy and surgery (ie, between diagnosis and treatment). We investigated whether consulting a GP presurgery was associated with time to surgery, postsurgical GP consultations or rectal cancer cases having surgery in a centre with radiotherapy facilities.

Results: Of the 407 patients, $43 \%(n=175)$ had at least one GP consultation between colonoscopy and surgery. The median time from colonoscopy to surgery was 27 days for those with an intervening GP consultation and 15 days for those without the consultation. $55 \%(n=223)$ had a GP consultation up to 30 days postsurgery; it was more common in cases of patients who consulted a GP presurgery than for those who did not $(65 \%$ and $47 \%$, respectively, adjusted OR 2.71, 95\% Cl 1.50 to $4.89, p=0.001$ ). Of the 142 rectal cancer cases, $23 \%(n=33)$ had their surgery in a centre with radiotherapy facilities, with no difference between those who did and did not consult a GP presurgery ( $21 \%$ and $25 \%$ respectively, adjusted OR $0.84,95 \% \mathrm{Cl} 0.27$ to $2.63, \mathrm{p}=0.76$ ).

Conclusions: Consulting a GP between colonoscopy and surgery was associated with a longer interval between diagnosis and treatment, and with further GP consultations postsurgery, but for rectal cancer cases it was not associated with treatment in a centre with radiotherapy facilities. GPs might require a more defined and systematic approach to CRC management.

\section{ARTICLE SUMMARY}

Article focus

- Primary healthcare providers have an important contribution to make in the process of colorectal cancer management. However, in Australia, the extent of GP involvement remains unknown as does their level of influence on the treatment referral pathway.

- We investigated the key patient clinical and demographic characteristics associated with consulting a GP between colonoscopy and surgery (ie, between diagnosis and treatment), for patients with colorectal cancer in New South Wales, Australia.

- We also investigated whether consulting a GP leading up to colorectal cancer surgery was associated with time between colonoscopy and surgery, consulting a GP after surgery or place of treatment for rectal cancer cases.

Key messages

- Less than half $(43 \%)$ of the patients who had a colonoscopy and surgery consulted a GP between the procedures; consulting a GP was associated with poorer health.

- Those who consulted a GP presurgery had longer time between colonoscopy and surgery and more commonly consulted a GP postsurgery, but rectal cancer cases were no more likely to have treatment in a centre with radiotherapy facilities.

- A more well-defined approach to CRC management by GPs might be required.

Strengths and limitations of this study

- A relatively large population-based sample of patients, with reliable information on GP consultations and surgical treatment for both public and private hospitals.

- We could not assess other treatment types and we did not have data on specific GP recommendations or physician specialties. 


\section{BACKGROUND}

Primary healthcare providers have an important contribution to make in the process of colorectal cancer (CRC) management. General Practitioners (GPs) refer a majority of patients with symptoms or positive screening tests for a diagnostic colonoscopy. ${ }^{1}$ Following diagnosis, GPs may continue to be involved in decision-making around definitive treatment and then subsequently during treatment, as well as in providing psychological support and management of comorbidities and side effects of cancer treatment. ${ }^{2-6}$ The coordination of care during this process is difficult for patients and health professionals, given the number and complexity of the services involved. ${ }^{7}$ Little is known about the extent of primary healthcare worker involvement in or their level of influence on the treatment referral pathway.

A patient may take one of multiple pathways prior and subsequent to diagnosis, ${ }^{8}$ and the lack of a clear referral pathway $^{9}$ may increase the time to treatment. Referrals are most frequently made to surgeons, followed by gastroenterologists and oncologists. ${ }^{10}$ In addition, patients often move back and forth between services. ${ }^{11}{ }^{12}$ In Australia, GPs refer patients for diagnostic colonoscopy and can be involved in the patient's subsequent decision to have treatment and post-treatment follow-up. However, little is known about the actual level of GP involvement in this pathway, which now also includes referral of patients who come into the referral pathway through the National Bowel Cancer Screening Program. In the programme, people turning 50, 55 or 65 are screened using a faecal occult blood test (FOBT), and those with a positive result are sent to their GP who refers them for further investigations. ${ }^{13}$ The relationship between the GP and the referral specialist may also be an important factor in determining the ongoing role of the GP during and after treatment. ${ }^{14}$ One study reported that the greater use of primary care prediagnosis is associated with better CRC outcomes, ${ }^{15}$ although it is a complex relationship that varies across cancer types. $^{16}$

Despite the availability of clinical guidelines, ${ }^{17}$ many CRC patients do not receive optimal care. ${ }^{18} 19$ The choices GPs make about referral of patients in certain health systems can have profound effects on patient outcomes. $^{20}$ A European study reported that 1-year cancer survival was lower in health systems where the GP acted as a 'gatekeeper'. ${ }^{21}$ Furthermore, a recent systematic review found a significant relationship between hospital case volume and short-term mortality for cancer surgery patients. ${ }^{22}$ However, inconsistent results mean that the relative importance of surgeon/hospital volume remains unclear, clouding the appropriateness of using case volume alone. ${ }^{22}$ Nevertheless, treatment in a multidisciplinary cancer centre with radiotherapy facilities is important for patient care, especially for rectal cancer cases. $^{23-26}$

The aim of this study was to use linked populationbased data to describe GP involvement in the referral pathway after diagnosis for CRC in New South Wales (NSW), Australia. This is one part of a four-phase study that also includes an audit of surgeons' referral letters and focus groups with clinicians and patients relating to the treatment referral pathway. ${ }^{14} 2728$ In this phase, we sought to determine whether there is an opportunity for GP involvement in patient care, as evidenced by GP consultations in the period between diagnosis and admission for surgery. We were also interested in whether presurgical GP consultations were associated with time to surgery, postsurgical GP consultations or, among rectal cancer cases, having surgery in a centre with radiotherapy facilities.

\section{METHODS}

\section{Data sources}

The data sources and linkage process for this study have been described in detail elsewhere. ${ }^{27}$ Briefly, we used linked records from the population-based 45 and $\mathrm{Up}$ Study, ${ }^{29}$ the NSW Central Cancer Registry (CCR), the NSW Admitted Patient Data Collection (APDC) and claims for medical services from Medicare Australia. The 45 and Up Study is a cohort study of 266000 NSW residents aged 45 years or more, sampled from the Medicare Australia registration database. ${ }^{29}$ Participants completed baseline questionnaires between January 2006 and May 2008 and consented to linkage to the other data collections used here. CCR records were obtained for people diagnosed with CRC between January 2001 and December 2007, along with APDC hospital separation records from July 2000 to June 2008 and claims for medical services through the Medicare Benefits Scheme (MBS) between June 2004 and January 2009.

Probabilistic linkage between the 45 and Up Study, the CCR and the APDC was done by the Centre for Health Record Linkage, ${ }^{30}$ as described previously, resulting in approximately $0.1 \%$ false-positive and $<0.1 \%$ falsenegative linkages. ${ }^{27}$ MBS claims records were linked by the Sax Institute using encrypted Medicare identification numbers. Ethical approvals for the 45 and Up Study, this specific study and the linkage were given by the University of NSW Human Research Ethics Committee and the NSW Population and Health Services Research Ethics Committee. The provision of Medicare records was approved by the Department of Health and Ageing Ethics Committee.

The group of interest comprised the 45 and Up Study participants who were diagnosed with CRC and had a colonoscopy leading up to their diagnosis as well as surgical treatment after diagnosis. Included cases were diagnosed from August 2004 to December 2007 and were linked with the APDC and MBS, so all cases had records for treatments and consultations at least 2 months prior to and at least 6 months after diagnosis.

The CCR provided data regarding the month and year of diagnosis, age, place of residence at diagnosis, disease 
stage (localised, regional, distant metastases or unknown) and cancer site (colon, or rectum including the rectosigmoid junction). We identified patients' comorbidities from APDC diagnosis codes, including cardiovascular disease, chronic obstructive pulmonary disease (COPD), diabetes and other diseases in the Charlson Comorbidity Index (other key comorbidities). ${ }^{31}$ Other sociodemographic characteristics (in table 1) were obtained from the self-completed 45 and Up Study baseline questionnaire.

\section{Procedures and consultations}

A specialist clinical panel identified relevant procedure codes and items for consultations, colonoscopies and surgery in the APDC and MBS. GP consultations were indicated by MBS items 1-51, 601-603, 700-719, 50005067 and 10 996-10 997. Surgical treatment comprised hemicolectomies, total colectomies, partial colectomies, total proctocolectomies, anterior rectal resections, Hartmann's procedure (rectosigmoidectomy), abdominoperineal resections and 'other' resections of the colon or rectum. Previous studies have shown that these data sources record over $90 \%$ of colonoscopies and surgical treatments for patients with cancer. $^{32}{ }^{33}$ Chemotherapy and radiotherapy are generally performed on an outpatient basis, for which data were not available, so they were not included in this study.

Diagnosis dates were available as month and year only, so chronology around diagnosis was based on calendar month and year. However, we were able to analyse the actual dates of GP consultations from the MBS and colonoscopies and surgeries from the APDC and MBS. We included surgical procedures performed in or after the month of diagnosis, and the last presurgery colonoscopy no earlier than 2 months prior to the month of diagnosis. For GP consultations occurring between colonoscopy and surgery, only consultations from the day of colonoscopy and at least 2 days prior to surgery were considered, to allow for the consultation to have an impact on the treatment pathway and to exclude consultations that were most likely for preoperative checks.

\section{Outcomes}

The primary outcome was the pattern of GP consultations between colonoscopy and surgery. This was then used as the key study factor in examining time between colonoscopy and surgery, patterns of GP consultations following surgery and, for rectal cancer cases, receiving surgery in a centre with radiotherapy facilities.

\section{Statistical analysis}

$\chi^{2}$ tests were used to compare patient groups and unconditional multivariable logistic regression identified factors associated with the outcomes of interest. Cox's proportional hazards regression was used to investigate factors associated with time between colonoscopy and surgery. Factors of interest included patient characteristics such as age, disease stage and place of residence.
Consultation of a GP between diagnosis and treatment was analysed for associations with time to surgery, having a GP consultation after surgery and, for rectal cancer cases, having treatment in a centre with radiotherapy facilities. Having a specialist consultation was considered a possible confounder and was included as a covariate. A small number of patients with missing values for variables of interest were excluded from analyses. All analyses were carried out in SAS V.9.1 (SAS Institute Inc, Cary, North Carolina, USA).

\section{RESULTS}

The study sample has been described in detail elsewhere. ${ }^{27}$ Briefly, 1023 CRC cases diagnosed between January 2001 and December 2007 were identified from the CCR among the first 102938 participants in the 45 and Up Study. The sample was restricted to 569 CRC cases diagnosed from August 2004 to December 2007 whose identifiers linked to the APDC and MBS. Of these, 407 cases $(72 \%)$ received surgery in or after the month of diagnosis and had a previous colonoscopy (up to 2 months before the month of diagnosis) (figure 1). These 407 cases are the ones in whose GP consultations we were interested; their characteristics are described in table 1.

\section{GP consultations between diagnosis and treatment}

Forty-three per cent $(n=175)$ of the 407 cases had at least one GP consultation between diagnosis and treatment (figure 2), with $23 \%$ having one consultation, $10 \%$ having two consultations and $9 \%$ having three or more consultations during that period. There were higher odds of consulting a GP between diagnosis and treatment for those who consulted a specialist prior to surgery, along with those reporting poorer health, those with diabetes, those without COPD, ever smokers and those who were diagnosed with CRC after participating in the 45 and Up Study (table 1).

\section{Time between diagnosis and treatment}

The median time from colonoscopy to surgery was 19 days; it was 27 days for those with and 15 days for those without an intervening GP consultation (figure 2). The time to surgery was more than 28 days for $43 \%$ of cases consulting a GP compared to $15 \%$ of patients who did not consult a GP. For those consulting a GP, the median time from colonoscopy to the first GP consultation was 7 days, and the median time of the last consultation prior to surgery was 10 days (including multiple GP consultations, excluding those 1 or 2 days presurgery). After adjusting for all covariates, the time from diagnosis to treatment remained significantly longer for patients who consulted a GP between diagnosis and treatment than for those who did not. This was also true for those who consulted a specialist between diagnosis and treatment compared with those who did not, and for rectal cancer cases compared with colon cancer 
Table 1 Characteristics of colorectal cancer (CRC) cases diagnosed between August 2004 and December 2007 that had colonoscopy and surgery, and characteristics associated with consulting a GP between colonoscopy and surgery ( $\mathrm{N}=407$ )

\begin{tabular}{|c|c|c|c|c|c|c|}
\hline \multirow[b]{2}{*}{ Category } & \multirow[b]{2}{*}{$\mathbf{n}$} & \multicolumn{2}{|c|}{ GP consult } & \multirow[b]{2}{*}{ Adjusted OR* } & \multirow[b]{2}{*}{$95 \% \mathrm{Cl}^{*}$} & \multirow[b]{2}{*}{ p Value† } \\
\hline & & $\bar{n}$ & Per cent & & & \\
\hline Sex & & & & & & 0.79 \\
\hline Woman & 152 & 64 & 42 & 1.10 & 0.56 to 2.15 & \\
\hline Man & 255 & 111 & 44 & 1.00 & (ref) & \\
\hline Age & & & & & & 0.77 \\
\hline$<60$ & 78 & 28 & 36 & 1.38 & 0.58 to 3.30 & \\
\hline $60-69$ & 108 & 42 & 39 & 1.13 & 0.57 to 2.28 & \\
\hline $70-79$ & 150 & 75 & 50 & 1.00 & (ref) & \\
\hline $80+$ & 71 & 30 & 42 & 1.50 & 0.62 to 3.65 & \\
\hline Country of birth & & & & & & 0.09 \\
\hline Australia & 320 & 141 & 44 & 1.00 & (ref) & \\
\hline Other & 81 & 30 & 37 & 0.50 & 0.22 to 1.12 & \\
\hline Unknown & 6 & 4 & 67 & Not incl. & Not incl. & \\
\hline Language spoken at home & & & & & & 0.41 \\
\hline English & 377 & 163 & 43 & 1.00 & (ref) & \\
\hline Non-English & 30 & 12 & 40 & 0.59 & 0.17 to 2.06 & \\
\hline Place of residence at diagnosis & & & & & & 0.62 \\
\hline Metropolitan & 186 & 75 & 40 & 1.00 & (ref) & \\
\hline Other urban & 103 & 45 & 44 & 0.63 & 0.24 to 1.62 & \\
\hline Rural & 118 & 55 & 47 & 1.65 & 0.58 to 4.69 & \\
\hline Type of housing & & & & & & 0.93 \\
\hline House & 296 & 130 & 44 & 1.00 & (ref) & \\
\hline Flat/unit & 50 & 19 & 38 & 1.17 & 0.46 to 2.93 & \\
\hline House on farm & 28 & 12 & 43 & 1.22 & 0.40 to 3.66 & \\
\hline Elderly accommodation & 26 & 11 & 42 & 0.79 & 0.24 to 2.58 & \\
\hline Other/unspecified & 7 & 3 & 43 & Not incl. & Not incl. & \\
\hline Socioeconomic status & & & & & & 0.27 \\
\hline Least disadvantaged quintile & 143 & 54 & 38 & 1.00 & (ref) & \\
\hline Quintile 2 & 64 & 28 & 44 & 1.65 & 0.58 to 4.69 & \\
\hline Quintile 3 & 126 & 55 & 44 & 1.17 & 0.43 to 3.21 & \\
\hline Quintile 4 & 58 & 28 & 48 & 2.40 & 0.87 to 6.60 & \\
\hline Most disadvantaged quintile & 16 & 10 & 63 & 3.18 & 0.63 to 16.01 & \\
\hline Highest education level attained & & & & & & 0.27 \\
\hline No school certificate/other & 48 & 22 & 46 & 1.20 & 0.47 to 3.09 & \\
\hline School/intermediate certificate & 102 & 41 & 40 & 1.00 & (ref) & \\
\hline Higher school/leaving certificate & 28 & 12 & 43 & 1.49 & 0.47 to 4.67 & \\
\hline Trade/apprenticeship & 56 & 21 & 38 & 1.01 & 0.40 to 2.55 & \\
\hline Certificate/diploma & 83 & 36 & 43 & 1.47 & 0.63 to 3.43 & \\
\hline University degree or higher & 80 & 37 & 46 & 2.94 & 1.19 to 7.26 & \\
\hline Unspecified & 10 & 6 & 60 & Not incl. & Not incl. & \\
\hline Marital status & & & & & & 0.08 \\
\hline Married/living as married & 288 & 120 & 42 & 1.00 & (ref) & \\
\hline Single/divorced/separated & 51 & 28 & 55 & 2.65 & 1.11 to 6.30 & \\
\hline Widowed & 65 & 26 & 40 & 1.03 & 0.44 to 2.39 & \\
\hline Unspecified & 3 & 1 & 33 & Not incl. & Not incl. & \\
\hline Income level & & & & & & 0.11 \\
\hline$<\$ 20 K$ p.a. & 112 & 51 & 46 & 1.00 & (ref) & \\
\hline$\$ 20 \mathrm{~K}-<\$ 40 \mathrm{~K}$ p.a. & 83 & 45 & 54 & 1.79 & 0.76 to 4.25 & \\
\hline$\$ 40 \mathrm{~K}-<\$ 70 \mathrm{~K}$ p.a. & 62 & 22 & 35 & 0.68 & 0.26 to 1.75 & \\
\hline$\$ 70 K+$ p.a. & 52 & 15 & 29 & 0.56 & 0.19 to 1.68 & \\
\hline Unspecified & 98 & 42 & 43 & 0.74 & 0.33 to 1.67 & \\
\hline Health insurance & & & & & & 0.19 \\
\hline Private with extras & 190 & 83 & 44 & 1.00 & (ref) & \\
\hline Private no extras & 70 & 26 & 37 & 0.45 & 0.21 to 0.97 & \\
\hline DVA/healthcare card & 101 & 46 & 46 & 1.20 & 0.55 to 2.62 & \\
\hline None of these & 37 & 16 & 43 & 0.67 & 0.24 to 1.85 & \\
\hline Missing & 9 & 4 & 44 & 1.24 & 0.24 to 6.47 & \\
\hline
\end{tabular}


Table 1 Continued

\begin{tabular}{|c|c|c|c|c|c|c|}
\hline \multirow[b]{2}{*}{ Category } & \multirow[b]{2}{*}{$\mathbf{n}$} & \multicolumn{2}{|c|}{ GP consult } & \multirow[b]{2}{*}{ Adjusted OR* } & \multirow[b]{2}{*}{$95 \% \mathrm{Cl}^{*}$} & \multirow[b]{2}{*}{ p Value } \\
\hline & & $\bar{n}$ & Per cent & & & \\
\hline \multicolumn{6}{|l|}{ BMI } & 0.21 \\
\hline Underweight/normal (<25 kg/m²) & 155 & 59 & 38 & 1.00 & (ref) & \\
\hline Overweight $\left(25-\leq 30 \mathrm{~kg} / \mathrm{m}^{2}\right)$ & 157 & 69 & 44 & 1.56 & 0.83 to 2.93 & \\
\hline Obese/morbidly obese $\left(\geq 30 \mathrm{~kg} / \mathrm{m}^{2}\right)$ & 66 & 31 & 47 & 1.30 & 0.58 to 2.94 & \\
\hline Null/not specified & 29 & 16 & 55 & 2.93 & 0.98 to 8.74 & \\
\hline \multicolumn{6}{|l|}{ Smoking status } & 0.05 \\
\hline Never smoker & 203 & 80 & 39 & 1.00 & (ref) & \\
\hline Ever smoker & 204 & 95 & 47 & 1.81 & 1.01 to 3.26 & \\
\hline \multicolumn{6}{|l|}{ Self-reported health status } & 0.002 \\
\hline Good-excellent & 307 & 115 & 37 & 1.00 & (ref) & \\
\hline Fair/poor & 78 & 47 & 60 & 2.76 & 1.30 to 5.82 & \\
\hline Unspecified & 22 & 13 & 59 & 5.60 & 1.59 to 19.81 & \\
\hline \multicolumn{6}{|l|}{ Cardiovascular disease } & 0.11 \\
\hline Yes & 47 & 26 & 55 & 2.09 & 0.85 to 5.13 & \\
\hline No & 360 & 149 & 41 & 1.00 & (ref) & \\
\hline \multicolumn{6}{|l|}{ COPD } & 0.04 \\
\hline Yes & 29 & 10 & 34 & 0.30 & 0.09 to 0.95 & \\
\hline No & 378 & 165 & 44 & 1.00 & (ref) & \\
\hline \multicolumn{6}{|l|}{ Diabetes } & 0.001 \\
\hline Yes & 50 & 33 & 66 & 5.15 & 2.02 to 13.16 & \\
\hline No & 357 & 142 & 40 & 1.00 & (ref) & \\
\hline \multicolumn{6}{|l|}{ Other key comorbidities } & 0.88 \\
\hline Yes & 56 & 26 & 46 & 0.94 & 0.40 to 2.18 & \\
\hline No & 351 & 149 & 42 & 1.00 & (ref) & \\
\hline \multicolumn{6}{|l|}{ Family history of CRC } & 0.51 \\
\hline Yes & 75 & 37 & 49 & 1.27 & 0.63 to 2.57 & \\
\hline No & 332 & 138 & 42 & 1.00 & (ref) & \\
\hline \multicolumn{6}{|l|}{ Disease stage } & 0.08 \\
\hline Localised & 185 & 73 & 39 & 1.00 & (ref) & \\
\hline Regional & 176 & 76 & 43 & 1.66 & 0.91 to 3.02 & \\
\hline Distant metastases & 27 & 13 & 48 & 1.57 & 0.47 to 5.19 & \\
\hline Unknown & 19 & 13 & 68 & 5.05 & 1.35 to 18.91 & \\
\hline \multicolumn{6}{|l|}{ Cancer site } & 0.52 \\
\hline Colon & 265 & 114 & 43 & 1.00 & (ref) & \\
\hline Rectum & 142 & 61 & 43 & 1.21 & 0.68 to 2.18 & \\
\hline \multicolumn{6}{|l|}{ Year of diagnosis } & 0.64 \\
\hline 2004 & 43 & 17 & 40 & 1.24 & 0.46 to 3.36 & \\
\hline 2005 & 113 & 43 & 38 & 0.93 & 0.44 to 1.93 & \\
\hline 2006 & 111 & 56 & 50 & 1.46 & 0.72 to 2.95 & \\
\hline 2007 & 140 & 59 & 42 & 1.00 & (ref) & \\
\hline \multicolumn{6}{|c|}{ Timing of CRC diagnosis relative to the 45 and Up Study questionnaire } & 0.01 \\
\hline Before (prevalent) & 327 & 131 & 40 & 0.35 & 0.16 to 0.75 & \\
\hline After (incident) & 80 & 44 & 55 & 1.00 & (ref) & \\
\hline \multicolumn{6}{|c|}{ Specialist consultation between colonoscopy and surgery } & $<0.0001$ \\
\hline Yes & 285 & 156 & 55 & 17.64 & 7.71 to 40.34 & \\
\hline No & 122 & 19 & 16 & 1.00 & (ref) & \\
\hline
\end{tabular}

${ }^{*}$ Adjusted for all other variables in this table.

†Overall $p$ value from a multivariable logistic regression.

¥Calculated from self-reported weight $(\mathrm{kg}) /$ height $(\mathrm{m})^{2}$.

BMI, body mass index; CRC, colorectal cancer; COPD, chronic obstructive pulmonary disease; DVA, Department of Veterans' Affairs;

GP, general practitioner; Not incl.: this category was not included in logistic regression ( $n=26$ overall); Ref: reference category.

cases (table 2). Separate analyses for colon and rectal cancer cases found that for both cancer types there was a longer time to surgery for those consulting a GP or a specialist between diagnosis and treatment (table 3).

\section{GP consultations after treatment}

Twenty-six per cent $(26 \%, \mathrm{n}=106)$ of cases had a GP consultation up to 2 weeks postsurgery, $55 \% \quad(n=223)$ consulted a GP up to 30 days postsurgery and $80 \% \quad(n=327)$ consulted a GP up to 3 months postsurgery. After 


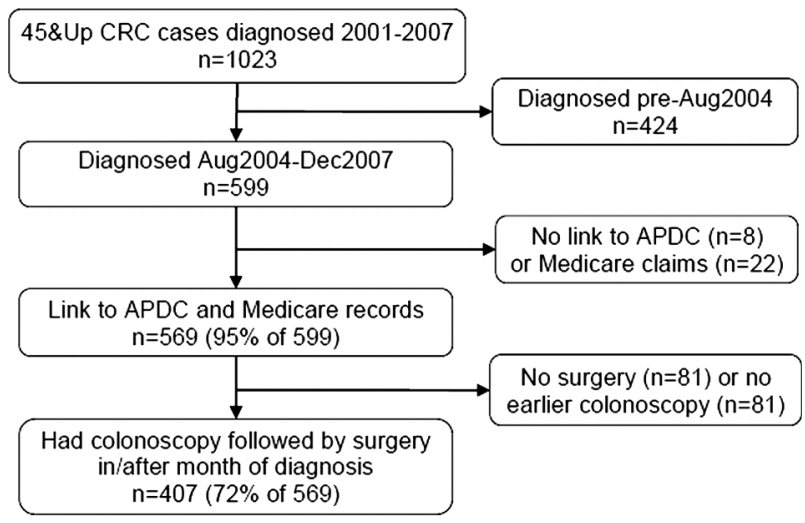

Figure 1 Selection of cases with colorectal cancer for analysis.

adjusting for all covariates, patients who consulted a GP in the interval between diagnosis and treatment were more likely to consult a GP in the 30 days postsurgery (65\% vs $47 \%$ for those not consulting a GP presurgery, OR $2.71,95 \%$ CI 1.50 to $4.89, \mathrm{p}=0.001$ ).

\section{Rectal cancer surgery in a centre with radiotherapy facilities}

Of the 142 rectal cancer cases, 23\% (n=33) had their surgery in a centre with radiotherapy facilities, $21 \%$ of those with and $25 \%$ of those without a presurgery GP consultation. After adjusting for key characteristics, there was no association between consulting a GP presurgery and having the surgery in a centre with radiotherapy facilities (OR 0.84 vs no presurgical GP consultation, $95 \%$ CI 0.64 to $2.35, \mathrm{p}=0.54$ ). An additional $21 \%$ had their surgery in a hospital colocated with a centre that had radiotherapy facilities, and a further $8 \%$ had a nonsurgical admission to a centre with radiotherapy facilities within the study period.

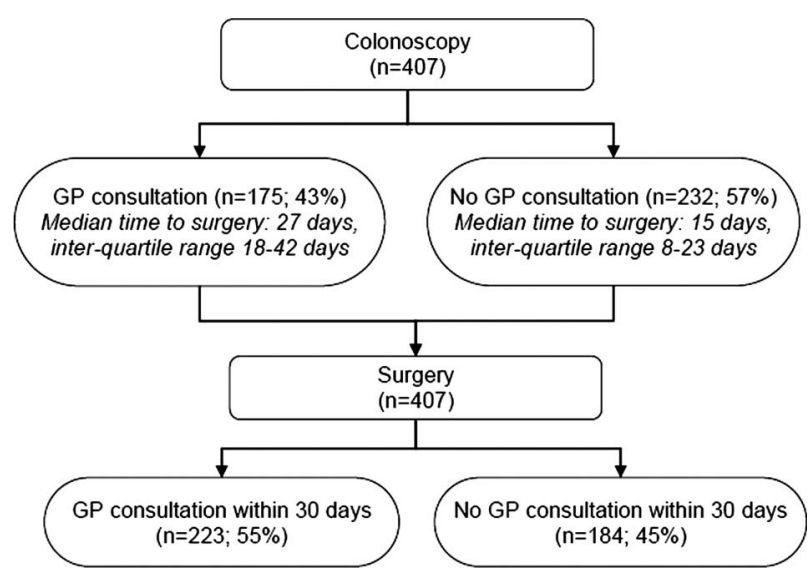

Figure 2 Flowchart of procedures and consultations for the 407 colorectal cancer cases who had a colonoscopy and surgery.

\section{DISCUSSION}

Around two in five newly-diagnosed CRC cases who had colonoscopy and surgery had a GP consultation between diagnosis and treatment, potentially allowing the GP to have some influence on individual patient treatment pathways. Having a GP consultation during this period was associated with longer time to surgery (but not necessarily causally) and consulting a GP postsurgery, but for rectal cancer cases it was not associated with treatment in a centre with radiotherapy facilities.

Having a GP consultation between diagnosis and treatment was more likely for cases with poorer self-reported health, those with diabetes, those without COPD and those who had ever been a smoker. Almost half of the patients who consulted a GP between diagnosis and treatment had more than one consultation during this time period. This suggests that GP consultations may be occurring for the most appropriate group: coordinating the care of those patients at higher risk because of poor general health.

The time from colonoscopy to surgery was substantially longer (a difference in medians of 12 days) for patients who consulted a GP between diagnosis and treatment, even after adjustment for cancer site, comorbidities, disadvantage and health status. However, we were unable to determine whether there was a causal link between GP consultations and time to surgery; it may be that a longer time period simply allows a greater opportunity for GP consultations in the interval. It could also be due to more patients who consulted a GP having presurgical radiotherapy. If increased time to surgery was a consequence of the engagement of the GP, this may have allowed a more considered decision by the GP about the optimal referral pathway with the increased interval being unlikely to have a material influence on the physical outcome, although it may raise psychological issues for the patient. ${ }^{34} 35$ It is worth considering if there are other ways in which GPs could be involved in decisions regarding care following diagnosis that do not increase the interval between diagnosis and treatment. This might include arranging follow-up GP visits sooner after the colonoscopy, especially as the first GP consultation was a median of 7 days afterwards. It might also include earlier email, text or telephone communication between the GP and the patient to initiate a referral.

Having a GP consultation after surgery was more likely for patients who consulted a GP in the lead-up to surgery, suggesting a greater continuity of primary care for these cases. Again, this might be especially appropriate for those who had comorbidities or poorer health status. It might also assist lower socioeconomic patients who, because of poorer health literacy, may have had more difficulty navigating the complexities of the healthcare system.

Given the importance of being able to offer radiotherapy for rectal cancer, ${ }^{17}$ we investigated any potential association between presurgical GP consultations and 
Table 2 Demographic and clinical characteristics associated with time between colonoscopy and colorectal cancer (CRC) surgery for all CRC cases $(\mathrm{N}=407)$

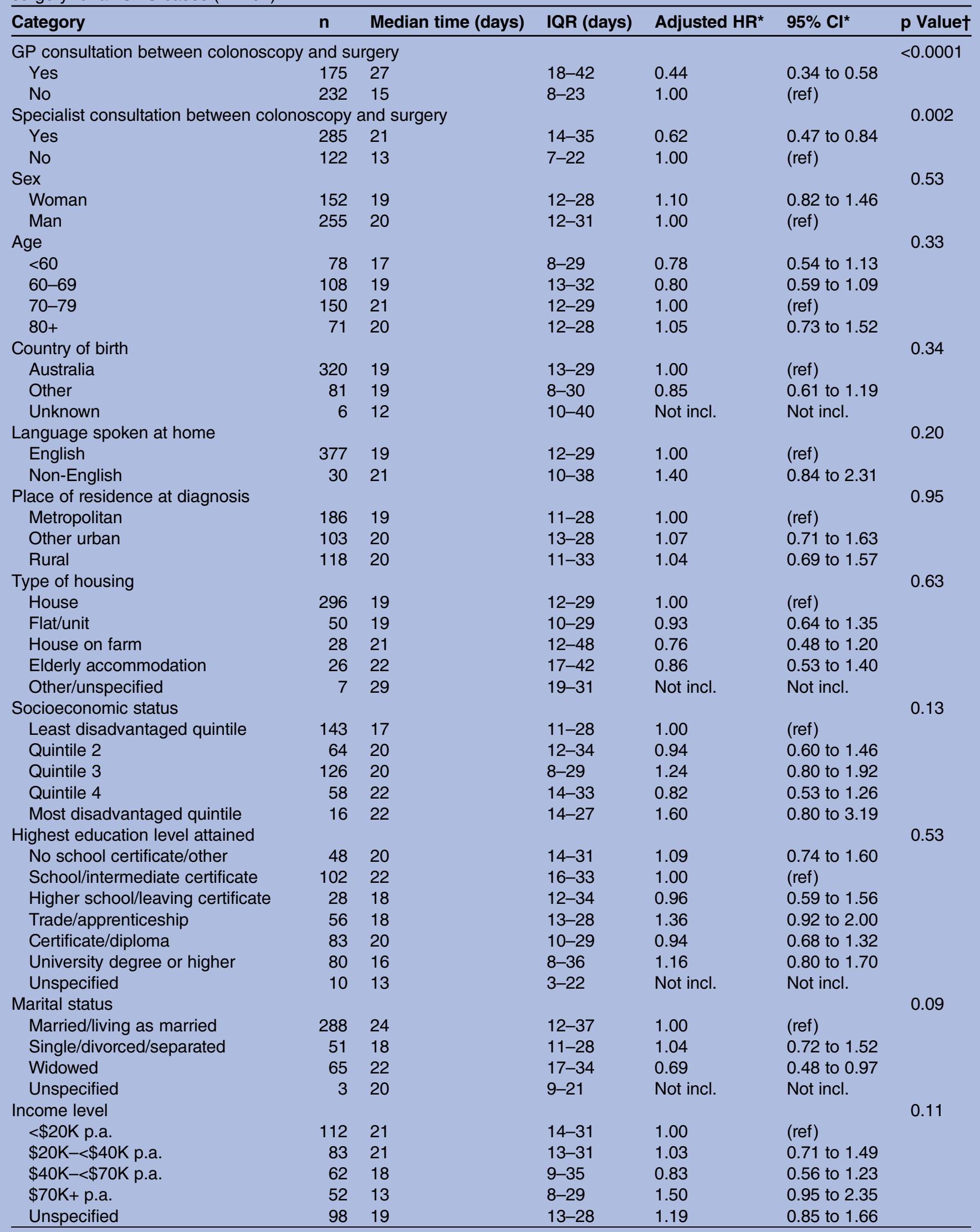


Table 2 Continued

\begin{tabular}{|c|c|c|c|c|c|c|}
\hline Category & $\mathbf{n}$ & Median time (days) & IQR (days) & Adjusted HR* & $95 \% \mathrm{Cl}^{*}$ & p Value \\
\hline \multicolumn{6}{|l|}{ Health insurance } & 0.42 \\
\hline Private with extras & 190 & 18 & $9-28$ & 1.00 & (ref) & \\
\hline Private no extras & 70 & 17 & $11-28$ & 1.01 & 0.73 to 1.40 & \\
\hline DVA/healthcare card & 101 & 21 & $14-29$ & 0.90 & 0.66 to 1.24 & \\
\hline None of these & 37 & 28 & $19-41$ & 0.67 & 0.44 to 1.03 & \\
\hline Missing & 9 & 25 & $16-28$ & 1.09 & 0.51 to 2.33 & \\
\hline \multicolumn{6}{|l|}{ BMI } & 0.48 \\
\hline Underweight/normal $\left(<25 \mathrm{~kg} / \mathrm{m}^{2}\right)$ & 155 & 18 & $10-28$ & 1.00 & (ref) & \\
\hline Overweight $\left(25-<30 \mathrm{~kg} / \mathrm{m}^{2}\right)$ & 157 & 20 & $12-35$ & 0.86 & 0.66 to 1.13 & \\
\hline Obese/morbidly obese $\left(\geq 30 \mathrm{~kg} / \mathrm{m}^{2}\right)$ & 66 & 22 & $13-31$ & 0.95 & 0.68 to 1.34 & \\
\hline Null/Not specified & 29 & 19 & $11-29$ & 0.72 & 0.45 to 1.15 & \\
\hline \multicolumn{6}{|l|}{ Smoking status } & 0.33 \\
\hline Never smoker & 203 & 19 & $10-29$ & 1.00 & (ref) & \\
\hline Ever smoker & 204 & 19 & $12-30$ & 1.13 & 0.89 to 1.44 & \\
\hline \multicolumn{6}{|l|}{ Self-reported health status } & 0.37 \\
\hline Good-excellent & 307 & 18 & $11-29$ & 1.00 & (ref) & \\
\hline Fair/poor & 78 & 21 & $15-40$ & 0.89 & 0.64 to 1.23 & \\
\hline Unspecified & 22 & 22 & $14-28$ & 0.70 & 0.41 to 1.21 & \\
\hline \multicolumn{6}{|l|}{ Cardiovascular disease } & 0.77 \\
\hline Yes & 47 & 20 & $9-29$ & 0.95 & 0.65 to 1.38 & \\
\hline No & 360 & 19 & $12-30$ & 1.00 & (ref) & \\
\hline \multicolumn{6}{|l|}{ COPD } & 0.47 \\
\hline Yes & 29 & 20 & $11-27$ & 1.19 & 0.74 to 1.92 & \\
\hline No & 378 & 19 & $12-30$ & 1.00 & (ref) & \\
\hline \multicolumn{6}{|l|}{ Diabetes } & 0.18 \\
\hline Yes & 50 & 26 & $14-36$ & 1.30 & 0.89 to 1.90 & \\
\hline No & 357 & 19 & $11-29$ & 1.00 & (ref) & \\
\hline \multicolumn{6}{|l|}{ Other key comorbidities } & 0.67 \\
\hline Yes & 56 & 20 & $12-29$ & 1.08 & 0.76 to 1.52 & \\
\hline No & 351 & 19 & $12-30$ & 1.00 & (ref) & \\
\hline \multicolumn{6}{|l|}{ Family history of CRC } & 0.99 \\
\hline Yes & 75 & 20 & 13-33 & 1.00 & 0.75 to 1.34 & \\
\hline No & 332 & 19 & $12-29$ & 1.00 & (ref) & \\
\hline \multicolumn{6}{|l|}{ Disease stage } & 0.08 \\
\hline Localised & 185 & 19 & $13-29$ & 1.00 & (ref) & \\
\hline Regional spread & 176 & 19 & $10-29$ & 1.16 & 0.91 to 1.48 & \\
\hline Distant metastases & 27 & 20 & $12-39$ & 0.73 & 0.43 to 1.21 & \\
\hline Unknown & 19 & 35 & $13-48$ & 0.65 & 0.37 to 1.16 & \\
\hline \multicolumn{6}{|l|}{ Cancer site } & $<0.0001$ \\
\hline Colon & 265 & 18 & $10-27$ & 1.00 & (ref) & \\
\hline Rectum & 142 & 22 & $14-37$ & 0.58 & 0.45 to 0.74 & \\
\hline \multicolumn{5}{|l|}{ Year of diagnosis } & & 0.53 \\
\hline 2004 & 43 & 19 & $9-26$ & 1.32 & 0.86 to 2.02 & \\
\hline 2005 & 113 & 19 & $12-29$ & 1.01 & 0.75 to 1.37 & \\
\hline 2006 & 111 & 21 & 14-32 & 1.13 & 0.84 to 1.52 & \\
\hline 2007 & 140 & 18 & $11-32$ & 1.00 & (ref) & \\
\hline \multicolumn{6}{|c|}{ Timing of CRC diagnosis relative to the 45 and Up questionnaire } & 0.61 \\
\hline Before (prevalent) & 327 & 19 & $11-29$ & 1.09 & 0.79 to 1.50 & \\
\hline After (incident) & 80 & 21 & 14-31 & 1.00 & (ref) & \\
\hline
\end{tabular}

*Adjusted for all other variables in this table (HR<1 indicates longer time between colonoscopy and surgery).

tOverall $\mathrm{p}$ Value from the Cox proportional hazards regression.

$\ddagger$ Calculated from self-reported weight $(\mathrm{kg}) /$ height $(\mathrm{m})^{2}$.

BMI, body mass index; CRC, colorectal cancer; DVA, Department of Veterans' Affairs; GP, general practitioner; COPD, chronic obstructive pulmonary disease; IQR, interquartile range; Not incl.: this category was not included in proportional hazards regression ( $n=26$ overall); ref: reference category.

surgery in hospitals with radiotherapy facilities, reflecting another aspect of continuity of care. For rectal cancer cases, having a GP consultation prior to surgery was not associated with having a surgical procedure in a centre with radiotherapy facilities. Fewer than one in four had their surgery in a centre with radiotherapy facilities, although this increased to around one in two when allowing for surgery in hospitals colocated with 
Table 3 Demographic and clinical characteristics associated with time between colonoscopy and colorectal cancer surgery, for colon and rectum cancer cases

\begin{tabular}{|c|c|c|c|c|c|c|}
\hline \multirow[b]{2}{*}{ Category } & \multicolumn{3}{|c|}{ Colon cancer $(n=265)$} & \multicolumn{3}{|c|}{ Rectal cancer $(n=142)$} \\
\hline & Adjusted HR $^{\star}$ & $95 \% \mathrm{Cl}$ & p Value† & Adjusted HR $^{\star}$ & $95 \% \mathrm{Cl}$ & p Valuet \\
\hline \multicolumn{3}{|c|}{ GP consultation between colonoscopy and surgery } & 0.001 & & & $<0.0001$ \\
\hline Yes & 0.54 & 0.38 to 0.79 & & 0.25 & 0.13 to 0.48 & \\
\hline No & 1.00 & (ref) & & 1.00 & (ref) & \\
\hline \multicolumn{3}{|c|}{ Specialist consultation between colonoscopy and surgery } & 0.01 & & & 0.01 \\
\hline Yes & 0.57 & 0.38 to 0.86 & & 0.41 & 0.21 to 0.79 & \\
\hline No & 1.00 & (ref) & & 1.00 & (ref) & \\
\hline \multicolumn{3}{|l|}{ Country of birth $\ddagger$} & 0.36 & & & 0.01 \\
\hline Australia & 1.00 & (ref) & & 1.00 & (ref) & \\
\hline Other & 1.22 & 0.80 to 1.87 & & 0.37 & 0.17 to 0.78 & \\
\hline \multicolumn{3}{|l|}{ Marital status $\ddagger$} & 0.28 & & & 0.02 \\
\hline Married/living as married & 1.00 & (ref) & & 1.00 & (ref) & \\
\hline Single/divorced/separated & 0.92 & 0.54 to 1.58 & & 1.52 & 0.70 to 3.26 & \\
\hline Widowed & 0.68 & 0.42 to 1.10 & & 0.42 & 0.20 to 0.86 & \\
\hline \multicolumn{3}{|l|}{ Income level } & 0.13 & & & 0.03 \\
\hline <\$20K p.a. & 1.00 & (ref) & & 1.00 & (ref) & \\
\hline$\$ 20 \mathrm{~K}-<\$ 40 \mathrm{~K}$ p.a. & 0.78 & 0.46 to 1.31 & & 0.65 & 0.32 to 1.33 & \\
\hline$\$ 40 \mathrm{~K}-<\$ 70 \mathrm{~K}$ p.a. & 0.85 & 0.50 to 1.44 & & 0.30 & 0.12 to 0.75 & \\
\hline$\$ 70 K+$ p.a. & 1.62 & 0.88 to 2.99 & & 0.52 & 0.19 to 1.41 & \\
\hline Unspecified & 0.91 & 0.58 to 1.42 & & 1.07 & 0.52 to 2.21 & \\
\hline \multicolumn{3}{|l|}{ Health insurance } & 0.02 & & & 0.01 \\
\hline Private with extras & 1.00 & (ref) & & 1.00 & (ref) & \\
\hline Private no extras & 0.67 & 0.43 to 1.04 & & 1.71 & 0.88 to 3.33 & \\
\hline DVA/healthcare card & 0.54 & 0.36 to 0.80 & & 3.36 & 1.56 to 7.24 & \\
\hline None of these & 0.51 & 0.27 to 0.95 & & 0.79 & 0.35 to 1.78 & \\
\hline Missing & 0.46 & 0.14 to 1.58 & & 2.09 & 0.63 to 6.99 & \\
\hline \multicolumn{3}{|l|}{ Disease stage } & 0.02 & & & 0.72 \\
\hline Localised & 1.00 & (ref) & & 1.00 & (ref) & \\
\hline Regional spread & 1.17 & 0.85 to 1.62 & & 0.79 & 0.48 to 1.30 & \\
\hline Distant metastases & 0.66 & 0.35 to 1.25 & & 0.60 & 0.18 to 2.01 & \\
\hline Unknown & 0.43 & 0.21 to 0.89 & & 1.13 & 0.29 to 4.38 & \\
\hline
\end{tabular}

another hospital that has a radiotherapy centre. Others have previously reported the potential underutilisation of specialist cancer centres for patients with rectal cancer. $^{25} 26$

This study is subject to a number of limitations. The 45 and Up Study had a response rate of $18 \%$ (similar to other cohort studies of this nature) and oversampled people from rural areas. While the 45 and Up Study participants resemble the general population in many respects, they are in general of higher socioeconomic status and more 'healthy'. ${ }^{36}$ However, empirical data from the study show risk estimates relating to a wide range of exposures and outcomes in the cohort are very similar to those calculated using 'representative' population survey data. ${ }^{36}$ We did not include treatment with chemotherapy or with radiotherapy as the available data were not comprehensive for all people receiving these treatments, and nor did we have information on patients' decisions regarding treatment. These may have influenced the place of treatment and explained some of the differences in the time to surgery. We analysed rectal cancer surgery in hospitals with radiotherapy facilities as an indicator that all cancer treatment modalities were available at one centre, thereby making it a more comprehensive cancer facility. This could have been improved with information regarding patients' decisions, GPs' recommendations and the specialties of all physicians involved in the care of each patient.

It is difficult to sort out the cause and effect of GP visits and an increased interval between diagnosis and treatment using these data alone as the Medicare data do not identify the reasons for GP visits. It may have been in relation to CRC or some other preexisting illness. Similarly, we could not determine the nature of 
specialist consultations, and a longer time to surgery for those with a specialist consultation could be beneficial if it means patients are getting the most appropriate treatment. Furthermore, we did not have information on individual physicians or their specialties, so we could not assess other aspects potentially related to the referral pathway, such as whether the colonoscopy was performed by a gastroenterologist or a surgeon, or whether the same surgeon then carried out the surgical procedure.

The National Bowel Cancer Screening Program was started in August 2006, ${ }^{13}$ but this study does not fully address what happens in the presence of the screening programme. In this programme, a GP refers a patient to colonoscopy after a positive FOBT result and is then involved in the referral process for cases diagnosed with CRC. The programme is being expanded to include people in other age groups, ${ }^{13}$ giving a further opportunity for GP involvement. This means that there is some urgency to optimise the potential benefits of engagement of GPs (eg, in providing better guidance about where to refer), and a need to address the potential reasons for an increased interval between diagnosis and treatment associated with consulting a GP, especially for patients with rectal cancer.

\section{Conclusion}

This is one of the first studies to examine the role of the GP in the pathway following CRC diagnosis and prior to surgery. Less than half of the patients had a GP consultation in this period, but those who did appeared to be among those who most needed it. The association between consulting a GP pretreatment and posttreatment is a strong rationale for GP engagement in the early stages of the patient pathway and will improve longterm continuity of care. Further research is needed to explore the directions of the association between GP visits and the interval between diagnosis and treatment. However, a more systematic approach might be needed for GP involvement in the treatment pathway, perhaps including official guidelines from primary care/GP organisations. This would not only encourage GP involvement, but it would also ensure that this does not lead to unnecessary delays.

\section{Author affiliations}

${ }^{1}$ Cancer Research Division, Cancer Council NSW, Sydney, New South Wales, Australia

${ }^{2}$ UNSW Research Centre for Primary Health Care and Equity, Sydney, New South Wales, Australia

${ }^{3}$ Liverpool Health Service, Collaboration for Cancer Outcomes Research \& Evaluation, Sydney, New South Wales, Australia

${ }^{4}$ Cancer Council Australia, Sydney, New South Wales, Australia

${ }^{5}$ UNSW St Vincent's Clinical School, Sydney, New South Wales, Australia

${ }^{6}$ Faculty of Health Sciences, University of Adelaide, Adelaide, New South Wales, Australia

${ }^{7}$ Faculty of Health Sciences, University of Sydney, Sydney, New South Wales, Australia

${ }^{8}$ Centre for Population Health Services, University of Edinburgh, Edinburgh, Scotland
Acknowledgements This research was completed using data collected through the 45 and Up Study (http://www.45andUp.org.au). The 45 and Up Study is managed by the Sax Institute in collaboration with a major partner Cancer Council New South Wales; and partners the Heart Foundation (NSW Division); NSW Ministry of Health; beyondblue: the national depression initiative; Ageing, Disability and Home Care, NSW Family and Community Services and the Red Cross Blood Service. We thank the many thousands of people participating in the 45 and Up Study. We thank the NSW Central Cancer Registry, the NSW Ministry of Health and Medicare Australia for making data available for analysis and the NSW Centre for Health Record Linkage for conducting record linkage. We also thank the other members of the Colorectal Cancer Referral Pathways Study Team: John Stubbs, Lisa Crossland and Rohan Gett.

Contributors DLO'C and MH helped conceive the study, advised on the data analysis and helped draft the manuscript. DG assisted with obtaining the data and data management, undertook the analysis and drafted the manuscript. SP, AS, CV, DW, I0, JB and MB helped conceive the study, participated in its coordination, and helped draft the manuscript. All authors read and approved the final manuscript.

Funding This work was supported by Cancer Australia (2007; a Priority-driven Collaborative Cancer Research Scheme (510348)).

\section{Competing interests None.}

Ethics approval NSW Population and Health Services Research Ethics Committee; University of NSW Human Research Ethics Committee.

Provenance and peer review Not commissioned; externally peer reviewed.

Data sharing statement No additional data are available.

\section{REFERENCES}

1. National Cancer Intelligence Network (UK): Routes to diagnosisNCIN data briefing. 2010. http://www.ncin.org.uk/publications/ data_briefings/routes_to_diagnosis.aspx (accessed 8 Nov 2012).

2. Klabunde $\mathrm{CN}$, Ambs $\mathrm{A}$, Keating NL, et al. The role of primary care physicians in cancer care. J Gen Intern Med 2009;24:1029-36.

3. Banou E, Hobfoll SE, Trochelman RD. Loss of resources as mediators between interpersonal trauma and traumatic and depressive symptoms among women with cancer. $J$ Health Psychol 2009;14:200-14.

4. Rasic DT, Belik SL, Bolton JM, et al. Cancer, mental disorders, suicidal ideation and attempts in a large community sample. Psychooncology 2008;17:660-7.

5. Coyne JC, Palmer SC, Shapiro PJ, et al. Distress, psychiatric morbidity, and prescriptions for psychotropic medication in a breast cancer waiting room sample. Gen Hosp Psychiatry 2004;26:121-8.

6. Department of Health. A policy framework for commissioning cancer services: a report by the expert advisory group on cancer to the chief medical officers of England and Wales. London: Department of Health, 1995.

7. Walsh J, Young JM, Harrison JD, et al. What is important in cancer care coordination? A qualitative investigation. Eur J Cancer Care 2011;20:220-7.

8. Barrett J, Jiwa M, Rose $\mathrm{P}$, et al. Pathways to the diagnosis of colorectal cancer: an observational study in three UK cities. Fam Pract 2006;23:15-19.

9. Scott MA, Knight A, Brown $\mathrm{K}$, et al. A single common urgent pathway for all colorectal referrals reduces time to diagnosis and treatment. Colorectal Dis 2006;8:766-71.

10. Charles J, Miller G, Valenti L. GI malignancies in Australian general practice. Aust Fam Physician 2006;35:186-7.

11. Department of Health. The NHS cancer plan. London, 2000.

12. National Health Priority Action Council (NHPAC). National health improvement framework for cancer. Canberra: Australian Government Department of Health and Ageing, 2006.

13. Department of Health and Ageing. National bowel cancer screening program http://www.cancerscreening.gov.au/internet/screening/ publishing.nsf/Content/bowel-about (accessed 8 Nov 2012).

14. Harris MF, Pascoe SW, Crossland LJ, et al. Referral pathways in colorectal cancer: findings from a qualitative study in general practice. Med J Aust 2011;195:178.

15. Ferrante JM, McCarthy EP, Gonzalez EC, et al. Primary care utilization and colorectal cancer outcomes among Medicare beneficiaries. Arch Intern Med 2011;171:1747-57. 
16. Lyratzopoulos G, Neal RD, Barbiere JM, et al. Variation in number of general practitioner consultations before hospital referral for cancer: findings from the 2010 national cancer patient experience survey in England. Lancet Oncol 2012;13:353-65.

17. Australian Cancer Network. Clinical practice guidelines for the prevention, early detection and management of colorectal cancer. Canberra: The Cancer Council Australia and Australian Cancer Network, 2005.

18. Spigelman AD. People with colorectal cancer: can we help them do better? ANZ J Surg 2004;74:401-2.

19. Young JM, Leong DC, Armstrong K, et al. Concordance with national guidelines for colorectal cancer care in New South Wales: a population-based patterns of care study. Med J Aust 2007:186:292-5.

20. Selby P, Gillis C, Haward R. Benefits from specialised care. Lancet 1996;348:313-18.

21. Vedsted $P$, Olesen $F$. Are the serious problems in cancer survival partly rooted in gatekeeper principles? An ecologic study. Br J Gen Pract 2011;61:e508-12.

22. Gruen RL, Pitt V, Green S, et al. The effect of provider case volume on cancer mortality: systematic review and meta-analysis. $C A$ Cancer J Clin 2009;59:192-211.

23. Hoffmann D, Moore J, Roder D. Trends in survival from colonic cancer: the impact of subspecialization. ANZ J Surg 1997;67:842-5.

24. Schrag D, Panageas KS, Riedel E, et al. Surgeon volume compared to hospital volume as a predictor of outcome following primary colon cancer resection. J Surg Oncol 2003;83:68-78.

25. Hillner BE, Smith TJ, Desch CE. Hospital and physician volume or specialization and outcomes in cancer treatment: importance in quality of cancer care. J Clin Oncol 2000;18:2327-40.

26. McArdle CS, Hole DJ. Influence of volume and specialization on survival following surgery for colorectal cancer. Br J Surg 2004:91:610-17.
27. Goldsbury D, Harris MF, Pascoe S, et al. Sociodemographic and other patient characteristics associated with time between colonoscopy and surgery, and choice of treatment centre for colorectal cancer: a retrospective cohort study. BMJ Open 2012;2: e001070.

28. Harris MF, Pascoe S, Crossland L, et al. Patients with colorectal cancer-a qualitative study of referral pathways and continuing care. Aust Fam Physician 2012;41:899-902.

29. Banks E, Redman S, Jorm L, et al. Cohort profile: the 45 and up study. Int J Epidemiol 2008;37:941-7.

30. Centre for Health Record Linkage (CHeReL): Centre for Health Record Linkage http://www.cherel.org.au (accessed 8 Nov 2012)

31. Charlson ME, Pompei P, Ales KL, et al. A new method of classifying prognostic comorbidity in longitudinal studies: development and validation. J Chronic Dis 1987;40:373-83.

32. Goldsbury DE, Armstrong K, Simonella L, et al. Using administrative health data to describe colorectal and lung cancer care in New South Wales, Australia: a validation study. BMC Health Serv Res 2012;12:387.

33. Goldsbury DE, Smith DP, Armstrong BK, et al. Using linked routinely collected health data to describe prostate cancer treatment in New South Wales, Australia: a validation study. BMC Health Serv Res 2011;11:253.

34. Sorbye SW, Risberg T, Norum J, et al. Cancer patients' perception of the examination period prior to treatment. Tidsskr Nor Laegeforen 1998;118:2468-70.

35. Risberg T, Sorbye SW, Norum J, et al. Diagnostic delay causes more psychological distress in female than in male cancer patients. Anticancer Res 1996;16:995-9.

36. Mealing NM, Banks E, Jorm LR, et al. Investigation of relative risk estimates from studies of the same population with contrasting response rates and designs. BMC Med Res Methodol 2010;10:26 